\title{
A conceptual framework for effective management of conflict risk within Agile software development environments
}

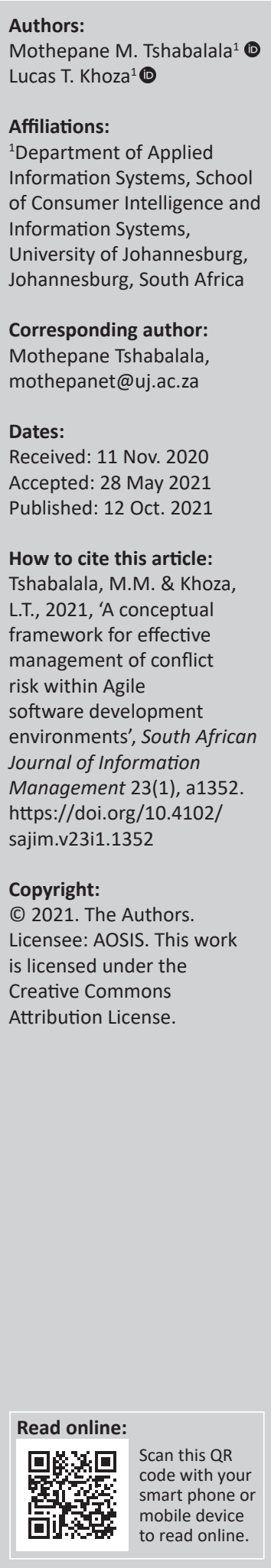

Background: Whenever teams obtain together to work towards a common goal, the lingering of an inherent conflict risk is always a possibility. This applies to software development teams as well. Researchers even argue this inherent conflict existence as necessary. Agile development environment is no exception. The main purpose for adopting Agile is to improve the technology adequacy to facilitate organisation competitiveness. Agile manages the achievement of this through its advocacy for change, adaptability and constant satisfaction of market demands. This is because Agile enables organisations to create software of quality standard that allows for quicker response to the continuously changing market needs of todays' world.

Objectives: Henceforth, this article investigates this topic to develop a conceptual framework for effectively managing conflict risk in Agile teams, to improve the organisation technology adequacy.

Method: This article employed quantitative methods for data collection and analysis. A structured online questionnaire was used for data collection and Statistical Package for the Social Sciences was used for data analysis. Pearson's correlation was used to test the relationships among variables.

Results: The findings show affirming results on the existence of conflict risk among Agile software development teams. The results indicate that there is a strong positive significant correlation between effective interaction, discussions and quality software application. Moreover, the findings demonstrate a strong relation between effective conflict management and achievement of set agile project goals.

Conclusion: Agile allows companies to address the market requirements while still being adaptive to constant change. However, the literature identifies conflict risk as one of the hindrances to realising this purpose.

Keywords: risk management; conflict management; IT projects; Agile approach; technology competitiveness.

\section{Introduction}

The world today is a hugely inter-connected competitive space that has created a critical demand for organisations to adapt and rise above the need to maintain their technological effectiveness and adequacy (Tokody 2018). The main drivers of the world's correct state have been mainly globalisation and digital transformation. These two elements have tremendously fuelled the constant demand and ever-changing demands of the market (World Economic Forum 2016:6). This has, in turn, requested organisations to be innovative and come up with techniques and methods they can employ to handle and manage this situation effectively and continuously (Kuteynikov et al. 2019:3964). The process and employment of technology across majority of industries and business sectors to curb this ongoing demand have been the cornerstone and answer for most organisations. This is known as 'technology competitiveness' (Berawi 2018:1). Technology competitiveness is the organisation's ability to provide products and services more effectively and efficiently than its current, relevant competitors using technology and digital means (Rodrigues \& José 2015:56). Mizanbekova, Bogomolova and Shatohina (2020) suggested that effective technology competitiveness facilitates companies to obtain higher market share, superior user experience and overall business excellence. The attaining of technology competitiveness in organisations provides the foundation for effective, successful response to the changing market demands (Mbelli \& Hira 
2016). One technique adopted in response to this need was the adoption of Agile.

Agile facilitates and improves the technology adequacy and effectiveness within organisations through its advocacy for change, adaptability and constant satisfaction of market demands (Rix et al. 2016). Through Agile, organisations can create software of quality standard, which allows for quicker response to the continuously changing market needs of todays' world (Choudhary \& Rakesh 2016). A proficient Agile environment within organisations facilitates successful, constructive interactions and collaborations among team members (Kiitam, McLay \& Pilli 2016). Constructive interactions and effective customer collaborations lead to successful continuous iterations, which then lead to high chances of successful project implementation and deployment (Gren \& Lenberg 2018). The constant, successful implementations of various Agile projects enable organisations to satisfy and fulfil the high competition-based market demands and requirements of this fast-paced market demands (Mbelli \& Hira 2016). This, in turn, improves the organisations' technological adequacy that helps organisations attain the strategic reason for adopting the Agile methodology.

However, according to existing literature, there is always one lingering negative element that is continuous to affect attainment of proficient, effective Agile environment, which, in turn, hinders organisations in achieving the benefits the study has outlined. Conflict is identified by the current literature a risk in software projects (Saxena, Venkatagiri \& Bandi 2016). According to Chiyangwa and Mnkandla (2018), project success depends heavily on a productive working atmosphere among project stakeholders, in particular projects implemented using the Agile methodology. Conflict-risk existence among project team members poses a risk to such effective working environment (Kiitam et al. 2016). The current literature further states that one solution to maintaining a productive working relation among project team members is effective management of the inherent conflict risk (Gren \& Lenberg 2018). Nesterkin and Porterfield (2016) suggested that constructive conflict-risk management features as a risk-reducing element within the global information technology (IT) development environments.

According to Adkins (2010), research paper that evaluates coaching techniques to constructive conflict management in Agile projects, conflict as a risk among Agile teams, is unavoidable, especially in comparison to other project environments. This is because Agile promotes for a more interdependent stakeholder environment to other project management methodologies, like the traditional waterfall (Gren 2017). The main aim of Agile approach concerning this interdependency among team members is the attainment of a broader viewpoint that is likely to come up with great, well-thought results (Mergel 2016). Effective conflict risk and Agile environments are two facets that need to be orderly and effectively coordinated to achieve organisation technology sufficiency (Saxena et al. 2016). Sudhakar (2015) stated that effective conflict-risk management delivers an improved and increased team maturity and effectiveness within Agile environments. Agile assists companies to fulfil the demand for the increasing ever-changing customer needs and requirements. This is achieved through continuous development of highquality standard software that supports organisations to constantly meet the customer needs of the ever-changing modern world of today (Balbes 2014).

The attainment of organisation's technology competitiveness is a direct result of the organisation's capability to stay on top of the competition through delivery of goods and services using technology (Morris, Ma \& Wu 2015). On the other hand, Agile facilitates organisation's capability to meet the continuous, flexible customer demands through the development of strategy-based systems or technology (Rigby, Sutherland \& Takeuchi 2016). This study investigates the influence of effectively managed conflict risk within Agile teams towards the organisations' technology competitiveness. To achieve this goal, the study will be guided by the following objectives:

- determine if there is any existing conflict risk within Agile development teams

- outline the nature of such risk and how it affects Agile environments, and the successful delivery of Agile projects

- develop a framework on how effectively managed conflict risk within Agile environments can facilitate the achievement of technology competitiveness within organisations.

\section{Problem statement}

Globalisation has forced organisations to think about business far beyond physical boarders (Bianchi \& Labory 2018). This created a critical urge for organisations to come up with ways to rise above and beyond this new way of business and realise profits. Information technology has been the main enabler of globalisation, and therefore, organisations have had to ensure efficiency and effectiveness of their IT (Ottonicar, Valentim \& Mosconi 2018). Successful delivery of IT systems over the last two decades has fostered the world to become the giant online space it is today. Effective management of IT development projects has been the cornerstone for such successful delivery (Ching \& Mutuc 2019). To improve on the success rate of IT development projects, companies adopted the Agile. Not only has this approach enabled organisations the flexibility to satisfy the constant changing market conditions and customer needs but has also positioned the world in a technology fuelled competition and readiness that facilitated digital transformation across the entire world's sectors and industries (Yanık \& Işılılı 2019). Conflict risk, which is inherent in project teams, is identified as a hindrance to the successful delivery of IT projects, Agile software development projects included (Saxena et al. 2016). 
Previous research has been conducted on conflict within Agile and the impact of effective conflict management within Agile environments. However, no research has directly linked the outcomes of effectively managed conflict risk within Agile environments towards organisations ability to attain technology competitiveness. Henceforth, this study aims to close this identified research gap.

\section{Literature review Conflict-risk management}

Globalisation has forced organisations to maintain an effective and efficient technology (Saniuk \& Saniuk 2018). Agile as a methodology largely adopted in software development environments facilities and manages this challenge of an unpredictable, ever-changing market demands through dependency on 'people and their creativity instead of on the processes' (Rix et al. 2016); however, wherever people are involved in groups, the risk of conflict risk is imminent. To achieve the benefits associated with the adoption of Agile, an effective team, which leads to effective projects implementation, is the foundation (Emejom et al. 2019). According to Chaudhry and Asif (2015), effective conflict-risk management is an organisation's strategic advantage and an enabler of efficient Agile development environment. Nevertheless, the 'trick' to this efficiency is effective mitigation of such conflict risk (Gren 2017). Conflict risk that is effectively mitigated yields positive team interactions and engagements (Gren 2017). Studies by Crawford et al. (2014), Sudhakar (2015) and Nesterkin and Porterfield (2016) agreed on the following benefits of effectively managed conflict risk within project teams:

- improved understanding that uplifts creativity

- it promotes existence of functional, constructive conflict within the team, which usually boosts levels of creativity and productivity over time

- fosters solid relationships among team members because they are skilled with sufficient conflict resolution techniques

- speedy problem-solving process and reduced tension because of a conflict resolution skilled team.

When there is accomplishment of the above benefits within an Agile environment, there is likelihood of successful, an effective team environment, which positively influences the attainment of successful implementations of various Agile projects within organisations (Sudhakar 2015).

According to Nesterkin and Porterfield (2016), effective conflict-risk management refers to the process of managing conflicts, and it entails the development of constructive strategies to mitigate the dysfunctions caused by conflict that arise in a group of people. Balbes (2014) supported this fact by suggesting that this escalates the constructive and productive outcomes of conflict that improves team effectiveness. Effectively managing conflict risk yields effective team relationships, and effective team relations then lead to effective communication, which is a critical element to any task success
(Deshpande 2014). Crawford et al. (2014) indicated that Agile teams require an effective conflict management strategy. This attains a strong mixture of constructive and negative outcomes of conflicts within projects, which then results in productive, solid team relationships (Gren 2017). Software projects success relies heavily on effective team relationships, because this affects the effectiveness of communication among team members (Deshpande 2014). The criticality of ensuring effective conflict-risk management within software development environments, specifically Agile environments, is one element that needs thorough investigation and possible solutions.

\section{Overview of agile}

Agile was first introduced as an iterative approach for software development (Beck et al. 2001). It is an approach to software development that employs rolling wave development, incremental and iterative delivery, rapid and flexible constant response to change and most importantly, advocates for communication between all project stakeholders, including team members and customers (Vithana, Asirvatham \& Johar 2019). Agile employs organisational models based on people, collaborations and overall shared values (PMI 2018). Agile entails an action or technique based on nimbleness, changeability, adaptiveness or flexibility (Balashova \& Gromova 2017). The idea of Agile or 'agility' has existed in the software sector since the 1990s and its success and wide adoption have been realised across the world (O'Leary, Cota \& Otis 2017). The Agile approach has insighted organisations to realise the benefit in valuing outcome over rules, encouraging broader participation over control, focussing on continual change response as well as promoting self-organisation over centralised governance (Khalil \& Kotaiah 2018). Agile is currently the vast adopted project management methodology within the IT development sector, with over $58 \%$ of companies implementing Agile or a hybrid of Agile and other methodologies, such as waterfall, scrum or six sigma (Asirvatham et al. 2018).

The current literature indicates the following as some of the main goals to implement IT projects in Agile (Ching \& Mutuc 2019; Shankarmani et al. 2012; Vithana et al. 2019):

- improved productivity

- delivery of right, quality software products

- meeting the project time-to-market constraint

- visibility and transparency among project teams

- stakeholder satisfaction

- an improved feedback mechanism.

Constant achievement of the above Agile software project goals facilitates digital transformations within organisations and provides organisations with the ability to keep up with the constant market demands (Mbelli \& Hira 2016). Effective response to the critical urge for digital transformation is the driver behind organisations' survival or failure in today's world. The success or failure mainly depends on the organisation's ability to provide products and services more effectively and efficiently than its current, relevant 
competitors using technology and digital means. This is what the existing literature refers to as technology competitiveness (Kohnová, Papula \& Salajová 2019).

\section{Research methodology}

This research study has been undertaken with an objective to investigate the theory of conflict-risk management in Agile teams and the impact it has on the organisations' technological competitiveness. According to Chaudhry and Asif (2015), conflict-risk management is defined as a process of managing the negative aspects that could hinder the success of software projects among project team members. Quantitative research techniques and tools were applied for data collection as well as data analysis. IBM SPSS was specifically used for data analysis. A structured questionnaire with closed-ended questions was used for data collection. In order to obtain in-depth understanding of conflict-risk management in Agile teams, purposive sampling method was deemed suitable. The questionnaire used Likert scales from Strongly Disagree to Strongly Agree. Purposive sampling method ensures that only experts or well-skilled and experience professionals participate in a research study. The unit analyses were professionals within IT sector, who are project team members involved in Agile software development within software developing organisations in South Africa. Because this study is quantitative, a positivism approach was followed (Kothari 2004). A total number of 179 responses were received and analysed. A total number of 13 items were tested for reliability and resulted in a Cronbach's Alpha of 0.738 which is acceptable (Tavakol \& Dennick 2011). The reliability statistics results are shown (Table 1). According to Mühl (2014), validity measures the instruments to ensure that they measure what they are expected to measure. Construct validity was used in this study.

\section{Study findings}

\section{Conflict-risk existence within Agile teams}

The findings depict several facts around the tested issues of conflict as a risk in Agile teams within South African (SA) companies. Firstly, the findings show affirming results on the existence of conflict risk among Agile teams in SA. The existing literature (Balbes 2014; Crawford et al. 2014; Gren

TABLE 1: Reliability statistics.

\begin{tabular}{lc}
\hline Items tested & $\begin{array}{c}\text { Cronbach's } \\
\text { alpha }\end{array}$ \\
\hline Effective conflict risk (five items tested). & 0.848 \\
Effective conflict-risk management in current teams (four items tested). & 0.778 \\
Current Agile project success criteria (four items tested). & 0.748 \\
Total (13 items tested). & 0.738 \\
\hline
\end{tabular}

TABLE 2: Conflict existence.

\begin{tabular}{lcc}
\hline Conflict-risk questions & $\begin{array}{c}\text { Frequency } \\
\text { (agree) }\end{array}$ & $\mathbf{\%}$ \\
\hline $\begin{array}{l}\text { Encountered any conflicts within the last month in your current } \\
\text { project. }\end{array}$ & 76 & 42 \\
$\begin{array}{l}\text { Overlooked any circumstance that could have likely resulted to } \\
\text { some disagreements in last month. }\end{array}$ & 89 & 50 \\
$\begin{array}{l}\text { Disagreement somehow affected the planned project work. } \\
\text { Disagreement somehow affected the continuous work relation. }\end{array}$ & 62 & 14 \\
Did you reach some sort of resolution regarding the disagreement? & 78 & 44 \\
\hline
\end{tabular}

2017) has tested this theory within Agile environments in other countries. Researchers such as Sudhakar (2015), Nesterkin and Porterfield (2016) and Gren and Lenberg (2018) have investigated conflict and its significant presence within software development teams. The study findings show that about 76/179 participants, which makes over $40 \%$ of the participants experienced conflict risk or some sort of disagreement within their respective Agile teams (Table 2). These findings correlate with Gren (2017), which indicated conflict as a risk within Agile teams. This shows tremendous importance on conflict as a risk element and its constructive management in teams to have smooth relations among team members who can lead to an effective working team environment. A need for an effective technique or method to mitigate and manage such risk is vital. The frequency results for conflict existence are shown (Table 2).

\section{Influence of conflict as a risk in Agile teams}

In addition to the questions on conflict-risk existence presented to participants concerning their current Agile teams, more questions on the impact of such risk were presented, which included: (1) to state whether most of the conflicts they experienced led to constructive discussions or dysfunctional, non-constructive disagreements. (2) Also, participants had to provide the outcomes of such conflictrisk effect on their team relations. (3) Lastly, participants were questioned on the existence of constructive ways of managing conflict risk within their respective Agile teams and its benefits towards set Agile teams (Table 3), project goals. The study findings on these tested theories as well as respective percentages of the quantitative data collected are shown (Figure 1 and Figure 2).

The study findings depicted two kinds of outcomes conflict existence brought within Agile (Table3) which are constructive as depicted (Figure 2) and dysfunctional conflict outcomes as depicted (Figure 1). The first outcome, constructive conflict,

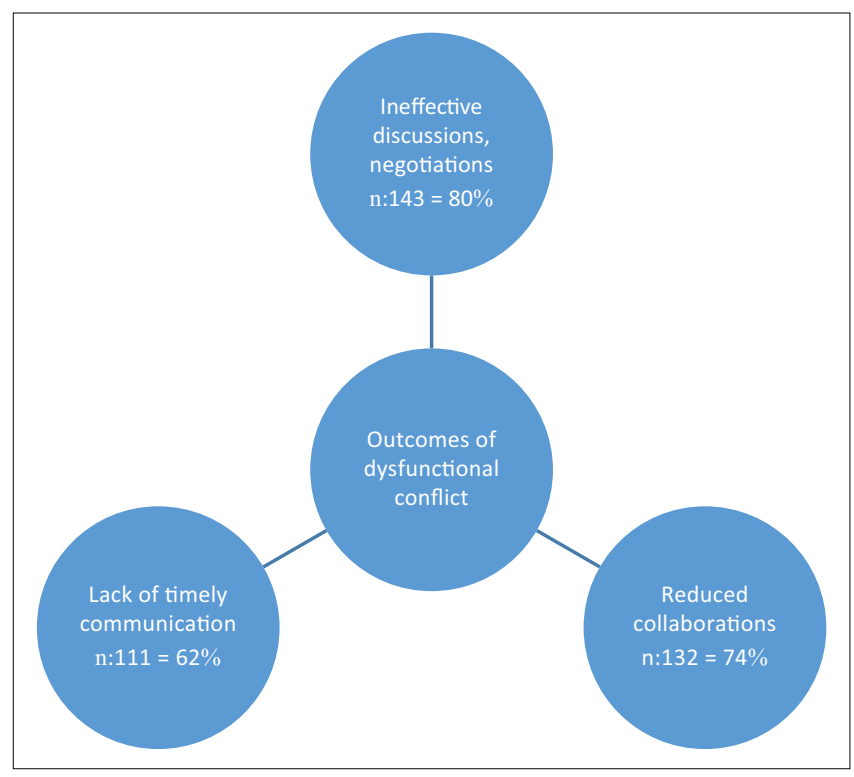

FIGURE 1: Dysfunctional conflict outcomes. 


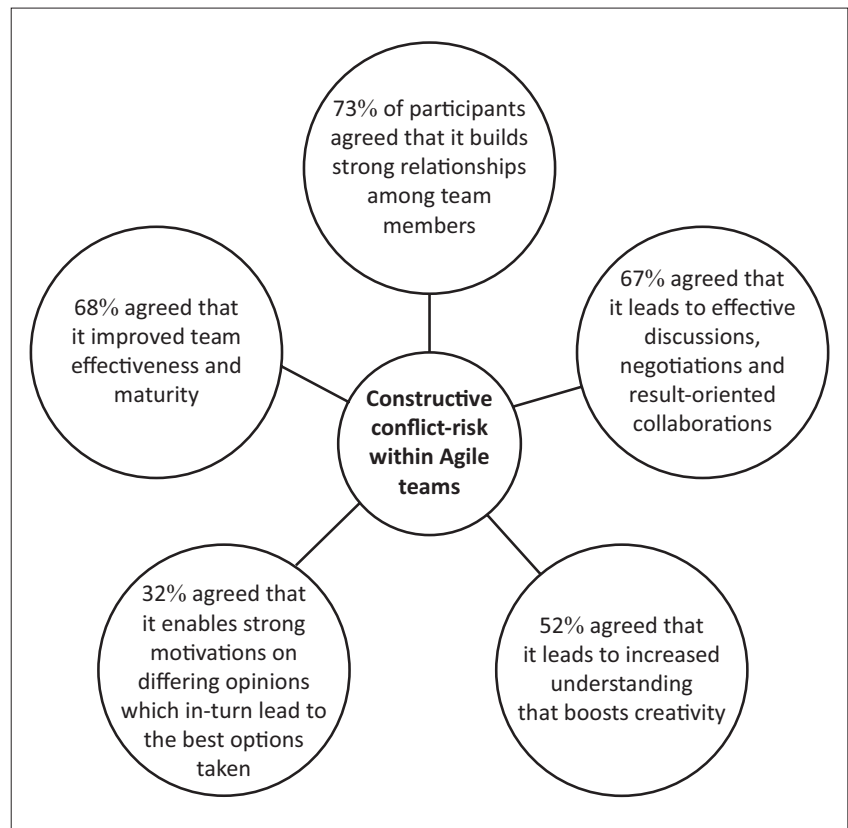

FIGURE 2: Constructive conflict outcomes.

TABLE 3: Impact of conflict existence.

\begin{tabular}{lcc}
\hline Variable & $\begin{array}{c}\text { Frequencies } \\
\text { (agree) }\end{array}$ & $\%$ \\
\hline Experience of constructive conflict? & 68 & 38 \\
Experience of dysfunctional conflict? & 111 & 62 \\
\hline
\end{tabular}

conveyed a positive effect within teams. This kind of conflict outcome was brought by effectively managed conflict risk, and this yielded a functional team environment. This finding on functional conflict and its tremendous advantages for an Agile environment is in line with the studies of Balbes (2014) that investigated the theory of making conflict management a strategic advantage within Agile teams.

The benefit of attaining the 'right product' because of functional conflict risk has been fully explored in a study by Crawford et al. (2014).

This study finding also determined the outcomes of constructive conflict in Agile teams, which concur with findings in the current literature by researchers Nesterkin and Porterfield (2016) and Thomas (2017). The other impact of conflict in Agile teams, identified by the study, is one that brings a negative impact to the working relations among team members. This occurs when conflict risk has not been effectively mitigated and managed. Various researchers including Chaudhry and Asif (2015) and Kiitam et al. (2016) have suggested that conflict risk within development teams most times brings negative outcomes because it yields to several repercussions like the lack of timely communication. A lack of timely communication then affects effective team discussions and negotiations as well as feedback, which reduces team performance.

TABLE 4: Correlations between benefits of effective conflict-risk management and Agile goals.

\begin{tabular}{|c|c|c|c|c|c|c|c|}
\hline Correlations & $\begin{array}{l}\text { Improved } \\
\text { productivity }\end{array}$ & $\begin{array}{l}\text { Quality software } \\
\text { application }\end{array}$ & $\begin{array}{l}\text { Right software } \\
\text { product }\end{array}$ & $\begin{array}{l}\text { Time-to-market } \\
\text { constraint }\end{array}$ & $\begin{array}{c}\text { Team } \\
\text { transparency and } \\
\text { effectiveness }\end{array}$ & $\begin{array}{c}\text { Client } \\
\text { satisfaction and } \\
\text { approval }\end{array}$ & $\begin{array}{c}\text { Effective input } \\
\text { and feedback } \\
\text { mechanism }\end{array}$ \\
\hline \multicolumn{8}{|c|}{ Strong team-member relationship } \\
\hline Pearson's correlation & $0.493 * *$ & 0.099 & 0.112 & $0.257 * *$ & $0.174 *$ & 0.051 & 0.039 \\
\hline Sig. (2-tailed) & 0.000 & 0.186 & 0.136 & 0.001 & 0.020 & 0.501 & 0.602 \\
\hline$N$ & 179 & 179 & 179 & 179 & 179 & 179 & 179 \\
\hline \multicolumn{8}{|c|}{ Effective interactions, discussions } \\
\hline Pearson's correlation & $0.224 * *$ & $0.776 * *$ & $0.419 * *$ & $0.214 * *$ & $0.334 * *$ & $0.206 * *$ & 0.092 \\
\hline Sig. (2-tailed) & 0.003 & 0.000 & 0.000 & 0.004 & 0.000 & 0.006 & 0.221 \\
\hline$N$ & 179 & 179 & 179 & 179 & 179 & 179 & 179 \\
\hline \multicolumn{8}{|l|}{ Team engagements } \\
\hline Pearson's correlation & $0.303 * *$ & $0.459 * *$ & $0.807 * *$ & $0.284 * *$ & $0.275 * *$ & 0.052 & $0.198 * *$ \\
\hline Sig. (2-tailed) & 0.000 & 0.000 & 0.000 & 0.000 & 0.000 & 0.491 & 0.008 \\
\hline$N$ & 179 & 179 & 179 & 179 & 179 & 179 & 179 \\
\hline \multicolumn{8}{|c|}{ Better team understandings } \\
\hline Pearson's correlation & $0.393 * *$ & $0.221 * *$ & $0.224 * *$ & $0.628 * *$ & $0.221 * *$ & 0.053 & $0.184 *$ \\
\hline Sig. (2-tailed) & 0.000 & 0.003 & 0.003 & 0.000 & 0.003 & 0.477 & 0.013 \\
\hline$N$ & 179 & 179 & 179 & 179 & 179 & 179 & 179 \\
\hline \multicolumn{8}{|c|}{ Team effectiveness and maturity } \\
\hline Pearson's correlation & $0.201 * *$ & $0.296 * *$ & $0.275 * *$ & $0.241 * *$ & $0.785 * *$ & 0.101 & $0.191 *$ \\
\hline Sig. (2-tailed) & 0.007 & 0.000 & 0.000 & 0.001 & 0.000 & 0.177 & 0.010 \\
\hline$N$ & 179 & 179 & 179 & 179 & 179 & 179 & 179 \\
\hline \multicolumn{8}{|c|}{ Productive negotiations } \\
\hline Pearson's correlation & $0.281 * *$ & $0.424 * *$ & $0.783^{*} *$ & $0.274 * *$ & $0.313 * *$ & 0.044 & $0.168^{*}$ \\
\hline Sig. (2-tailed) & 0.000 & 0.000 & 0.000 & 0.000 & 0.000 & 0.557 & 0.024 \\
\hline$N$ & 179 & 179 & 179 & 179 & 179 & 179 & 179 \\
\hline
\end{tabular}

*, Correlation is significant at the 0.05 level (2-tailed).

**, Correlation is significant at the 0.01 level (2-tailed).

Strong

Medium

Weak 
The correlations analysis between the benefits of effective conflict-risk management and Agile goals is shown (Table 4). The objective of this analysis was to check if there is any correlation between the two variables. To test the significant relationships if any, Pearson's correlation is used. According to Pallant (2016) with Pearson's correlation, it is also possible to determine the strength of the relationships above just showing relationships. This indicates how much each variable determines or correlates with other variables. The Pearson's correlations $r$ values indicate numbers between 0 and 1 and there are specific rules that guide the interpretation of these numbers (Fricker et al. 2019; Pallant 2016). The following rules according to Pallant (2016) apply when interpreting $r$ values to determine the strength of relationships:

- small $r=0.10$ to 0.29

- medium $r=0.30$ to 0.49

- large $r=0.50$ to 1.0 .

Based on the results (Table 4), the following were concluded.

- The results indicate that there is a strong positive significant correlation between effective interaction, discussions and quality software application $(r=0.776$ and $p=0.000)$. These results indicate that when teams continually interact during software projects development, the likelihood of the team to deliver quality software product is high. These results are inline with Freire et al. (2015) and Moe, Dingsøyr and Dybå (2010), stating that teams interact and communicate to deliver quality software projects.

- The results indicate that there is a strong positive significant correlation between team engagements and right software products $(r=0.807$ and $p=0.000)$. This is in relation to the Agile Manifesto's values. Vithana et al. (2019) stated that teams need to keep on engaging to deliver valuable software products, hence the string relationship between the two variables.

- The results indicate that there is a strong positive significant correlation between better team understandings and time-to-market constraints $(r=0.628$ and $p=0.000)$. As stated by Project Management Institute (2018), frequent delivery of working software is of utmost important when using Agile methodologies.

- The results indicate that there is a strong positive significant correlation between team effectiveness, maturity and team transparency and effectiveness $(r=0.807$ and $p=0.000)$. These results indicate that working with matured teams can result in effectiveness in software development process as indicated by Gren, Torkar and Feldt (2017).

- The results indicate that there is a strong positive significant correlation between productive negotiations and right software quality $(r=0.807$ and $p=0.000)$. Lack of negotiations can reduce teams' performance (Gren \& Lenberg 2018). With the strength of the relationship evident, it is therefore implied that in order to deliver right-quality software products, project team leaders must ensure all positive negotiations with all stakeholders involved.

\section{Conceptual framework for conflict-risk management}

Conflict as a risk in Agile teams has been explored in current literature; however, there is no research that has directly established a link between effective conflict-risk management within Agile teams towards organisations ability to attain technology adequacy and competitiveness. Researchers Crawford et al. (2014); Saxena et al. (2016) and Gren (2017) have investigated the conflict within Agile environments, its relative sources as well as means of handling and managing it to enable better team collaborations. Effective teams are the ground work for every successful organisation, and organisations generally fail at their strategic goals if they lack effective teams (Kiitam et al. 2016). Organisations without teams who work well together normally struggle, even with the simplest task implemented, while effective teams support in improved quality, facilitation of the completion of projects and aid in increasing productivity and efficiency (Anumah 2017). Effectiveness of the team is the foundation for successful Agile development and successful implementation of Agile projects (Hoda \& Noble 2017). Effective continuous delivery of successful Agile projects within the organisations is the foundation of the organisations' ability to keep up with the fast-paced technological world, and hence constantly be able to survive the technology-based competition and needs (Morris et al. 2015).

According to Galli (2018), team effectiveness can be described as the capability for a team to achieve the goals or objectives set by authorised employees or by the organisation. Agile methodology advocacy for frequent team interactions and constant customer collaborations throughout the project life cycle signifies that there should be some degree to effective management of disagreements that arise, as this would have a direct effect to future team interactions (Hummel, Rosenkranz \& Holten 2016). According to Crawford et al. (2014) and Balbes (2014), when conflict risk within Agile teams is mishandled and mismanaged, the effect of the risk becomes negative to the future team interactions and collaborations. However, when conflict risk is effectively managed, it leads to constructive sharing of views, ideas and opinions among team members (Crawford et al. 2014). The constructive sharing of views, ideas and opinions leads to smarter solutions of handling the project, and hence improves the team effectiveness (Balbes 2014). The results as indicated (Figure 3 ) illustrate that effective conflictrisk management enables Agile goals, while Agile goals facilitate organisational goals for adopting Agile to ensure that there is improved technology competitiveness.

\section{Discussions and implication of the study findings}

The study examined how constructive conflict in Agile teams affects the team-specific Agile goals, particularly the benefits of effective conflict management on set project Agile goals within Agile teams. To achieve this study objective, the researcher conducted a Pearson's correlation analysis among the variables that constitutes the outcomes of constructive 


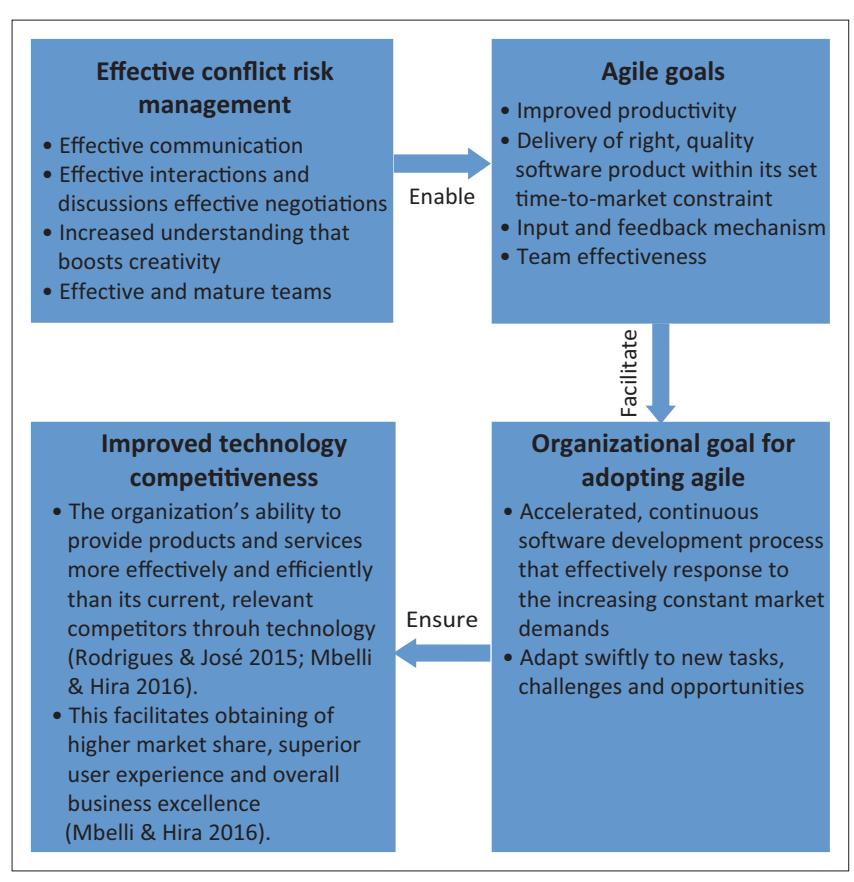

FIGURE 3: Conceptual framework of conflict-risk management.

conflict versus the variables that constitute Agile goals. The study findings highlight a strong connection between constructive conflict outcome, 'Effective interactions and discussion' on the achievement of, 'Improved Productivity', 'Delivery of right, quality software' that meets the set 'Timeto-market constraint' and 'Client satisfaction and approval'. 'Effective interactions and discussion' also facilitates 'Team transparency and effectiveness'. Moreover, the study can identify the constructive conflict outcomes; 'Team engagements', 'Team understanding', 'Team effectiveness and maturity', and 'Productive negotiations' as having a direct relation and connection on the achievement of specific Agile goals such as 'Team effectiveness', 'Effective input and feedback' and 'Improved Productivity, 'Delivery of right, quality product that meets the set time-to-market constraint'.

On the other hand, there is a constant significant highlight in the findings, which indicates that the specific Agile goal 'client satisfaction and approval' shares very limited correlation and relation towards majority of the constructive conflict outcomes. This particular finding shows that existence of conflict management within Agile teams has no apparent significance to the client' system approval or satisfaction.

These study findings are beneficial to all members and stakeholders of Agile developing environment because the results address:

- the issue of conflict as a risk in IT projects, particularly Agile projects

- the impact of effectively managed conflict in Agile environments, which the current literature identifies as a promoter of team effectiveness, which leads to the successful delivery of Agile development projects

- the impact of unmanaged conflict in Agile environments, which the current literature identifies as a facilitator of project failure
- most importantly validated how various outcomes of constructive conflict existence within project teams are directly related to the achievement of set Agile project goals, which, in turn, facilitates organisations ability to attain technology competitiveness.

\section{Conclusion}

This article has positively illustrated the relationship between an organisations technology competitiveness and effectively managed conflict risk in Agile teams. The findings show an extreme and vital role of conflict as a risk and its effective mitigation concerning an organisation's ability to maintain an effective technology adequacy, which can assist in its total success. The existing literature identified effective conflict-risk management as a constituent towards successful Agile projects. Constructive management of conflict among Agile teams fosters team effectiveness and continuous delivery of high-quality standard software product deliverables. This, in turn, facilitates organisations to maintain a productive and efficient response to the ongoing, changing customer demands using technology (Mbelli \& Hira 2016). This technology advantage enables organisations to then realise the benefits of technology investments made, including the adoption of Agile, and this encourages them to maintain further technology competitiveness (Rodrigues \& José 2015).

\section{Acknowledgements}

The authors appreciate the support and time provided by the University of Johannesburg, as well as their gratitude to everyone who completed the questionnaire to assist with the data collection process.

\section{Competing interests}

The authors affirm that they have no conflicting interests or relationships that may have improperly influenced them in writing this article.

\section{Authors' contributions}

M.M.T. conducted the conceptualisation, review of the literature and drafting of the article. L.T.K. was responsible for data analysis and review of the overall article.

\section{Ethical considerations}

This letter serves to confirm that the proposed research project has been granted ethical clearance by the School of Consumer Intelligence and Information Systems Ethics committee at the University of Johannesburg. Please refer to the report below for the ethical clearance number and specified conditions of approval.

\section{Funding information}

This research received no specific grant from any funding agency in the public, commercial or not-for-profit sectors. 


\section{Data availability}

The data that support the findings of this study are available from the corresponding author upon reasonable request.

\section{Disclaimer}

The views and opinions expressed in this article are those of the authors and do not necessarily reflect the official policy or position of any affiliated agency of the authors.

\section{References}

Adkins, L., 2010, Coaching Agile teams: A companion for ScrumMaster, Agile coaches, and project managers in transition, 'Reference \& Research Book News, August 2010, edited by 2020, Gale Academic OneFile, Ringgold, Inc., viewed 10 Novembe 2020, from https://link.gale.com/apps/doc/A233055093/AONE?u=rau_itw\&sid= AONE\&xid=bf9b25dd.

Anumah, I., 2017, Conflict management, eds. H. Ishola, J. Owolabi \& G. Akper Abuja: Adeniyan College of Education, viewed 11 May 2019, from www.nou. edu.ng.

Asirvatham, D., Vithana, N. \& Johar, G.M., 2018, An Empirical Study on Using Agile Methods in Global Software Development, 150-156. https://doi.org/10.1109/ ICTER.2018.8615505

Balashova, E.S. \& Gromova, E.A., 2017, 'Agile project management in telecommunications industry', Espacios 38(41), 30.

Balbes, M., 2014, Conflict and resolution in the Agile world, the Agile architect, viewed 11 May 2019, from https://adtmag.com/Articles/2014/12/17/Agile-ConflictResolution.aspx?p=1.

Beck, K. et al., 2001, Manifesto for Agile software development, The Agile alliance, viewed 15 May 2019, from http://Agilemanifesto.org/.

Berawi, M.A., 2018, 'The fourth industrial revolution: Managing technology development for competitiveness', International Journal of Technology 9(1), 1-4 https://doi.org/10.14716/ijtech.v9i1.1504

Bianchi, P. \& Labory, S., 2018, Industrial policy for the manufacturing revolution: Perspectives on digital globalisation, Industrial Policy for the Manufacturing Revolution: Perspectives on digital globalisation, Edward Elgar Publishing Limited Cheltenham.

Chaudhry, A.M. \& Asif, R., 2015, 'Organizational conflict and conflict management: A synthesis of literature', Journal of Business and Management Research 9(2015), 238-244.

Ching, P.M. \& Mutuc, J.E., 2019, 'Modeling the dynamics of an Agile scrum team in the development of a single software project', in IEEE International Conference on Industrial Engineering and Engineering Management, IEEM, Bangkok, December 16-19, 2018. https://doi.org/10.1109/IEEM.2018.8607430

Chiyangwa, T.B. \& Mnkandla, E., 2018, 'Agile methodology perceived success and its use: The moderating effect of perceived compatibility', South African Computer use: The moderating effect of perceived compatibility', South
Journal 30(2), 1-16. https://doi.org/10.18489/sacj.v30i2.554

Choudhary, B. \& Rakesh, S.K., 2016, 'An approach using Agile method for software development', in Proceedings of the 2016 International Conference on Innovation and Challenges in Cyber Security (ICICCS-INBUSH 2016), Greater Noida, India, and Challenges in Cyber Security (ICICCS-INBUSH 2016), Greater

Crawford, B., Soto, R., Barra, C., Crawford, K. \& Olguin, E., 2014, 'Agile Software Teams Can Use Conflict to Create a Better Products', Communications in Computer an Information Science 434, 24-29. https://doi.org/10.1007/978-3-319-07857-1_5

Deshpande, M.V., 2014, 'To analyze conflicts between software developer and software tester', International Journal of Innovative Research in Information Security (IJIRIS) 1(2), 21-25.

Emejom, A.A., Burgess, C., Pepper, D. \& Adkins, J., 2019, Agile Approaches for Successfully Managing and Executing Projects in the Fourth Industrial Revolution viewed n.d., from https://doi.org/10.4018/978-1-5225-7865-9.ch001

Freire, A.S., Da Silva, R.M., Perkusich, H., Almeida, H. \& Perkusich, A., 2015, 'Bayesian network model to assess Agile teams' teamwork quality', in Proceedings - 29th Brazilian Symposium on Software Engineering, SBES 2015. https://doi. org/10.1109/SBES.2015.29

Galli, B.J., 2018, 'Integrated model of teamwork for team effectiveness analysis: An empirical study', International Journal of Business and Systems Research (IJBSR) 12(4), 411-440. https://doi.org/10.1504/IJBSR.2018.095073

Gren, L., 2017, 'The links between Agile practices, interpersonal conflict, and perceived productivity', ACM International Conference Proceeding Series, EASE'17: Evaluation and Assessment in Software Engineering Karlskrona Sweden, June 15-16, 2017. https://doi.org/10.1145/3084226.3084269

Gren, L. \& Lenberg, P., 2018, 'The importance of conflict resolution techniques in autonomous Agile teams', ACM International Conference Proceeding Series, XP '18 Companion: 19th International Conference on Agile Software Development, Porto, Portugal May 21-25, 2018. https://doi.org/10.1145/3234152.3234185.

Gren, L., Torkar, R. \& Feldt, R., 2017, 'Group development and group maturity when building Agile teams: A qualitative and quantitative investigation at eight large companies', Journal of Systems and Software 124, 104-119. https://doi. org/10.1016/j.jss.2016.11.024
Hoda, R. \& Noble, J., 2017, 'Becoming Agile: A grounded theory of Agile transitions in practice', in Proceedings - 2017 IEEE/ACM 39th International Conference on Software Engineering, ICSE 2017, Buenos Aires, Argentina, May 20-28, 2017. Software Engineering, ICSE 2017, Bu

Hummel, M., Rosenkranz, C. \& Holten, R., 2013, 'The role of communication in Agile systems development: An analysis of the state of the art', Business and Information Systems Engineering 5(5), 343-355. https://doi.org/10.1007/
Instions Information System

Khalil, M.A. \& Kotaiah, B., 2018, 'Implementation of Agile methodology based on SCRUM tool', in 2017 International Conference on Energy, Communication, Data Analytics and Soft Computing, ICECDS 2017, Chennai, India, August 01-02, 2017. Analytics and Soft Computing, ICECDS 2017, Ch
https://doi.org/10.1109/ICECDS.2017.8389872

Kiitam, A., McLay, A. \& Pilli, T., 2016, 'Managing conflict in organisational change', International Journal of Agile Systems and Management 9(2), 114-134. https:// International Journal of Agile Systems
doi.org/10.1504/IJASM.2016.078575

Kohnová, L., Papula, J. \& Salajová, N., 2019, 'Internal factors supporting business and technological transformation in the context of industry 4.0', Business: Theory and Practice 20, 137-145. https://doi.org/10.3846/btp.2019.13

Kothari, C., 2004, Research methodology: Methods and techniques, New Age International, viewed 16 March 2019, from http://196.29.172.66:8080/jspui/ bitstream/123456789/2574/1/Research\%20Methodology.pdf.

Kuteynikov, D., Izhaev, O., Lebedev, V. \& Zenin, S., 2019, 'Transformation of public relations in the conditions of technological revolutions: Technology and innovation', International Journal of Recent Technology and Engineering 8(2), 3964-3971. https://doi.org/10.35940/ijrte.B2880.078219

Mbelli, T.M. \& Hira, J., 2016, 'The perceptions of Agile methodology in South Africa' Computer Science \& Information Technology 6, 219-227. https://doi.org/10.5121/ csit.2016.60119

Mergel, I., 2016, 'Agile innovation management in government: A research agenda', Government Information Quarterly 33(3), 516-523. https://doi.org/10.1016/j. giq.2016.07.004

Mizanbekova, S., Bogomolova, I. \& Shatohina, N., 2020, 'Prospects for digital and innovative technologies in management competitiveness of enterprises', Food Processing: Techniques and Technology 50(2), 372-383. https://doi. org/10.21603/2074-9414-2020-2-372-382

Moe, N.B., Dingsøyr, T. \& Dybå, T., 2010, ‘A teamwork model for understanding an Agile team: A case study of a Scrum project', Information and Software Technolog 52(5), 480-491. https://doi.org/10.1016/j.infsof.2009.11.004

Morris, L., Ma, M. \& Wu, P.C., 2015, 'Agile innovation: The revolutionary approach to accelerate success, inspire engagement, and ignite creativity', International Management Review (1), 1-400.

Mühl, J.K., 2014, 'Research methodology', Contributions to Management Science 4, 75-100. https://doi.org/10.1007/978-3-319-04069-1_4

Nesterkin, D. \& Porterfield, T., 2016, 'Conflict management and performance of information technology development teams', Team Performance Management 22, 242-256. https://doi.org/10.1108/TPM-05-2016-0018

O'Leary, J., Cota, R. \& Otis, G., 2017, 'Successful Agile in government: Supporting the product owner', Agile in Government: A playbook from the Deloitte Center for
Government Insights, pp. 24-32, viewed 07 April 2019, from https://www2. deloitte.com/content/dam/insights/us/articles/3897_Agile-in-government/DUP_ Agile-in-Government-series.pdf.

Ottonicar, S.L.C., Valentim, M.L.P. \& Mosconi, E., 2018, 'A competitive intelligence model based on information literacy: Organizational competitiveness in the context of the $4^{\text {th }}$ Industrial Revolution', Journal of Intelligence Studies in Business 8(3), 55-65. https://doi.org/10.37380/jisib.v8i3.366

Pallant, J., 2016, 'For the SPSS survival manual website, go to this is what readers from around the world say about the SPSS Survival Manual ', Automotive Industries Al, 181(4), 718

Project Management Institute, 2018, Success in disruptive times: expanding the value delivery landscape to address the high cost of low performance, Pulse of the Profession, viewed 23 June 2019, from https://www.pmi.org/-/media/pmi/ documents/public/pdf/learning/thought-leadership/pulse/pulse-of-theprofession-2018.pdf.

Rigby, D.K., Sutherland, J. \& Takeuchi, H., 2016, Embracing agile: How to master the process that's transforming management, Harvard Business Review 94(5), 40-50.

Rix, M., Kujat, B., Meisen, T. \& Jeschke, S. 2016, 'An Agile information processing framework for high pressure die casting applications in modern manufacturing systems', Procedia CIRP, 41, 1084-1089. https://doi.org/10.1016/j.procir. systems', Proce

Rodrigues, M.G. \& José, F., 2015, 'Technology and competitiveness: Technological innovation for developing economies growth', International Journal of Advances innovation for developing economies growt
in Management and Economics 4(4), 57-65.

Ronald, D. Fricker Jr., Burke, K., Han, X. \& Woodall, W.H., 2019, 'Assessing the Statistical Analyses Used in Basic and Applied Social Psychology After Their p-Value Ban', The American Statistician 73(Suppl 1), 374-384. https://doi.org/10.1080/00031305.2 American Sta
018.1537892

Saniuk, S. \& Saniuk, A., 2018, 'Challenges of industry 4.0 for production enterprises functioning within cyber industry networks', Management Systems in Production Engineering 26(4), 212-216. https://doi.org/10.1515/mspe-2018Producti
0034

Saxena, A., Venkatagiri, S. \& Bandi, R.K., 2016, 'Managing inherent conflicts in Agile distributed development: Evidence from product development', in Proceedings of the 27th Australasian Conference on Information Systems, ACIS 2016, Wollongong, Australia, December 05-06, 2016. 
Shankarmani, R. et al., 2012, 'Agile methodology adoption: Benefits and constraints', International Journal of Computer Applications 58(15), 31-37. https://doi. org/10.5120/9361-3698

Sudhakar, G.P., 2015, 'A review of conflict management techniques in projects', Brazilian Journal of Operations \& Production Management 12(2), 214-232. https://doi.org/10.14488/BJOPM.2015.v12.n2.a3

Tavakol, M. \& Dennick, R., 2011, 'Making sense of Cronbach's alpha', Internationa Journal of Medical Education 2, 53-55. https://doi.org/10.5116/ijme.4dfb.8dfd

Thomas, K.W., 2017, Making conflict management a strategic advantage, White Paper Conflict. Edmonton: Vopel, Klaus W., Psychometrics, Edmonton, AB.
Tokody, D., 2018, 'Digitising the European industry - Holonic systems approach', Procedia Manufacturing 22, 1015-1022. https://doi.org/10.1016/j.promfg. 2018.03.144

World Economic Forum, 2016, 'Digital transformation of industries: Digital enterprise, World Economic Forum, viewed 25 June 2019 from https:/www.accenture com/ acnmedia/Accenture/Conversion-Assets/WEF/PDF/Accenture-Digital-Enterprise.pdf.

Yanık, S. \& Işıklı, E., 2019, 'An ANP approach for prioritizing the Agile Project Management Criteria in Industry 4.0 Transition', in H. Bolat \& G. Temur (eds.) Agile Approaches for Successfully Managing and Executing Projects in the Fourth Industrial Revolution, pp. 165-187, IGI Global. http://doi:10.4018/978-1-52257865-9.ch009 